\title{
The preposition under and its noun collocates in the under-NOUN pattern: A quantitative corpus-based investigation
}

\begin{abstract}
This paper adopts a usage-based perspective on grammatical structure (Goldberg 2006, 2013) and the attraction-reliance measure (Schmidt 2000; Schmid \& Küchenhoff 2013) to gauge the reciprocal interaction between a noun and the preposition under in the under-NOUN pattern: in other words, to determine strongly attracted nouns of this preposition. On the basis of the data extracted from the academic part of the Corpus of Contemporary American English (COCA), this paper seeks to show that there are nouns that are more strongly attracted to the preposition under than others and that the co-occurrences of particular nouns with this preposition are more significant than others. In addition, the results of the analysis seem to suggest that the mutual associations between particular nouns and this preposition depend upon different senses of under and are therefore motivated by conceptual metaphors, metonymies, and/or image schemas.
\end{abstract} Keywords: construction grammar, COCA, attraction-reliance measure, corpus-based approach.

\section{Introduction}

English prepositions have generated considerable research interest among cognitive linguists (e.g., Lakoff 1987; Brugman 1988; Lindstromberg 1996, 2001, 2010; Tyler \& Evans 2001; Evans \& Tyler 2005; Radden \& Dirven 2007). This research interest is stimulated by increasing recognition of the importance of prepositions when structuring a sentence and in marking special relationships between persons, objects, and locations, coupled with evidence that prepositions are one of the most difficult areas of acquisition for second language learners, and sustained by the fact that the semantic nature of many prepositions presents a number of problems for both teachers and learners.

1 Address for correspondence: Institute of Linguistics and Literary Studies, Siedlce University of Natural Sciences and Humanities, ul. Żytnia 39, 08-100 Siedlce, Poland. E-mail: jaroslaw.wilinski@uph.edu.pl 
In particular, numerous researchers (Brugman 1988; Dewell 1994; Boers 1996; Tyler \& Evans 2003; Evans \& Tyler 2004a,b; Brenda 2014) have focused on applying insights from Cognitive Linguistics (CL) to the semantics of English propositions to determine cognitive motivation for their meanings. Brugman (1988), for example, offered a detailed semantic analysis of the preposition over as a radial category, whereas Tyler and Evans (2003) and Evans and Tyler (2004a,b) examined various aspects of English prepositions from a CL standpoint and argued that cognitive linguistics findings, which systematize and link the multiple senses of prepositions, offer a more systematic account of the semantics of English prepositions than the more traditional accounts that currently underpin the majority of pedagogical grammars. By focusing on various senses associated with particular prepositions in a systematic way, Evans and Tyler (2004a,b) explored the semantic network of prepositions and proposed perceiving prepositions on the basis of their association to proto-scenes (highly schematic spatial scenes or the primary meanings related to specific prepositions). Hence, prepositions and their uses are represented as a coherent network of related senses. Evans and Tyler (2005: 15) provided a model of English prepositions in which "the various senses are represented as gestaltlike conceptualizations of situations or scenes which are systematically connected, rather than a series of discrete dictionary-type definitions strung together in a list".

Many scholars (Lindstromberg 1996; Boers \& Demecheleer 1998; Littlemore 2009; Evans \& Tyler 2005; Archard \& Niemeier 2004; Cho 2010; Song et al. 2015) have adopted a cognitive linguistic approach to teaching English prepositions with the argument that the multiple uses of prepositions can be perceived as related in systematic ways, which carries important pedagogical implications. For example, Lindstromberg (1996) argued in favor of employing Lakoff's (1987) prototype theory for teaching prepositions. From this perspective, prepositions are assumed to have a small number of related meanings, among which one is prototypical (i.e., spatial or physical). In addition, some of the literal meanings of a preposition are extended by metaphors and metonymies to create another small set of related senses. Therefore, some figurative meanings can be explained by extending their prototypical meaning.

However, little or no attention has hitherto been paid to the quantification of nouns co-occurring with a particular preposition in a specific pattern, the statistical corroboration of their co-occurrence in academic discourse, or the empirical substantiation of previous hypotheses about their use. Previous empirical research has provided little statistical information about the frequency of occurrence of English prepositions and nouns and their distribution in different types of discourse or corpora and are thus restricted either in scope of interest or quantitative data investigated. For example, Boers's (1996) corpus-based study into English prepositions associated with the UP-DOWN and the FRONT-BACK dimensions only aimed at comparing British and American corpora regarding the dimensions used to describe given abstract relations by focusing 
on providing the overall distribution (in numbers of instances) of the prepositions over the three corpora (the L.O.B. Corpus, the Brown Corpus, and the Corpus of English Conversation), and on giving the relative contribution of literal and figurative senses. No previous study has attempted to investigate the mutual association between nouns and prepositions in a particular pattern and to identify nouns associated with the preposition under scrutiny. The aim of this paper is therefore to show that the preposition under displays a marked tendency to co-occur with particular categories of nouns in the under-NOUN pattern, and the co-occurrence of specific nouns with this preposition is more significant than their use in other constructions.

The following portion of this paper is organized into five sections. Section 2 outlines the theoretical assumptions of cognitive linguistics relevant for the discussion of the preposition over, and it presents a corpus-based method for identifying the most strongly attracted nouns of the under-NOUN pattern. Section 3 describes the corpus, the data, and the tools, as well as the statistical procedure adopted in this investigation. Section 4 addresses semantic properties of the preposition under followed by a brief overview of the research related to the preposition under from a CL perspective. Section 5 integrates the theory and practice by incorporating the findings of the quantitative analysis into a semantic description of nouns collocating with the preposition under. The article concludes with a few remarks about the results of this study, observations about the efficacy of using a quantitative corpus-based approach for analyzing prepositions and their noun collocates, and suggestions for future experimental research on prepositions.

\section{Theoretical and methodological background}

The investigation is founded on the concepts and theoretical assumptions that pertain to usage-based construction grammar (Goldberg 1995, 2006, 2013), a cognitive approach to metaphor and metonymy (Lakoff \& Johnson 1980; Kövecses 2010; Kövecses \& Radden 1998), and the theory of image schemas (Johnson 1987; Oakley 2007; Mandler \& Pagán Cánovas 2014).

The usage-based concept of grammar (Bybee 2010; Goldberg 2006; Hilpert 2014; Langacker 2008) rests on two fundamental principles. First, linguistic structure consists of constructions. A construction is a complex linguistic sign that links a specific structural pattern with a particular meaning or function (see Diessel 2015, 2017). The expression under control, for instance, instantiates a phrasal construction consisting of the preposition under and a noun that combines with this preposition (under-NOUN). Second, language use and linguistic development are shaped by the same cognitive processes as other, nonlinguistic forms of cognition and social behavior (e.g., conceptualization, social cognition, and memory and processing). One aspect that plays a pivotal role in shaping linguistic knowledge is frequency of occurrence. Since frequency determines the representation of grammatical knowledge in memory, it enhances the activation 
and processing of lexical items, categories, and constructions, which in turn can influence the development and structure of the linguistic system (Arnon \& Snider 2010; Bybee \& Hopper 2001; Bybee 2006, 2007, 2010; Goldberg 2006).

The Conceptual Theory of Metaphor (Kövecses 2010, 2015, 2016) rejects the idea that metaphor is solely a figure of speech, or a rhetorical device that is peripheral to language and thought. Instead, the theory assumes that metaphor is fundamental to our conceptual system and therefore fundamental to language. Conceptual metaphors are shared by members of a linguistic community and play an important role in structuring and understanding abstract concepts. From this perspective (Kövecses 2010), metaphor is defined as understanding one concept in terms of another (usually a more concrete concept). For example, as Lakoff and Johnson (1980) noted, the abstract concept CONTROL can be understood by means of the spatial orientation UP-DOWN (the source concept), thus reflecting the two orientational metaphors: HAVING CONTROL OR FORCE IS UP and BEING SUBJECT TO CONTROL OR FORCE IS DOWN. The phrase under control is a highly conventionalized metaphorical expression, and its meaning is dependent on the conceptual metaphor in question. Recent research, however, has shown that metaphorical meaning is not only a matter of cognition but is also dependent on a multitude of contextual factors, including situational, discourse, and conceptual-cognitive contexts (see Kövecses 2015, 2016), and therefore should be interpreted from a linguistic, cognitive, discourse-functional, and socio-cultural perspective (Gonzálvez-García et al. 2013).

A cognitive approach to metonymy (Kövecses 2010; Kövecses \& Radden 1998; Radden \& Kövecses 1999) rests on the premise that metonymy is a cognitive process in which the vehicle (thing, event, property), a conceptual element or entity, is used to provide mental access to the target, which is another conceptual entity such as a thing, event, or property within the same frame or domain (Kövecses \& Radden 1998: 39). This can be conceptualized as "within-domain mapping," where the vehicle entity is mapped onto the target entity (Kövecses 2006: 99). Thus, for example, given the AGE domain, the sentence If you prove the baby is his and prove the girl was under age when the baby was conceived, that's statutory rape directs attention, or provides mental access, to the conceptual element 18 years old (target) through the use of another conceptual element age (vehicle) that belongs to the same frame. In this case, age is used metonymically to stand for a specific number (eighteen).

The theory of image schemas is a semantic theory associated with the works of Johnson (1987), Lakoff (1987), Hampe (2005), Oakley (2007), and Mandler and Pagán Cánovas (2014). The term image schema refers to "a recurring dynamic pattern of our perceptual interactions and motor programs" that organizes and structures our experiences (Johnson 1987: xiv, xvi). In other words, image schemas are embodied preconceptual structures that derive from, or are grounded in, human recurrent bodily movements through space, perceptual interactions, and ways of manipulating objects 
(Hampe 2005: 1). The UP-DOWN schema, an orientational schema discussed by Lakoff (1987: 267), is an example of an image schema relevant to the discussion of the preposition under and its noun collocates in the current study. This schema arises from sensory and perceptual experience: that is, our physiology (the vertical axis of the human body) and the presence of gravity give rise to meaning as a result of how we interact with our environment. According to Lakoff and Johnson (1980), the UP-DOWN schema provides the basis for abstract concepts by virtue of serving as the source concept in metaphorical correspondences.

The methodology applied in this study is based on quantitative corpus linguistics. The method referred to as the attraction-reliance measure (Schmidt 2000; Schmid \& Küchenhoff 2013) is employed to determine the mutual association between nouns and the preposition under in the under-NOUN pattern. Attraction measures the extent to which the pattern under scrutiny attracts a particular noun, while reliance gauges the degree to which a given noun appears in this pattern versus other patterns in the corpus (Schmid \& Küchenhoff 2013: 548). The first calculation involves dividing the observed frequency of occurrence of a noun with the preposition under in the pattern by the total frequency of all nouns in this pattern, whereas the latter entails dividing the frequency of occurrence of a noun in the pattern in question by its frequency of occurrence in the whole corpus (Schmid 2000: 54). The results of these calculations are then expressed as percentages by multiplying the observed frequency of a noun in each case by one hundred. In this study, both computations were performed in Microsoft Excel. The percentage provided by both calculations was used as an index of attraction and reliance: the higher the percentage, the stronger the attraction and reliance.

Strictly quantitative and objective as this corpus-based technique might seem with respect to the way in which the reciprocal interaction between a noun and the preposition under in the construction in question is determined, the quantitative findings are assessed qualitatively and subjectively. In other words, noun collocates that exert the strongest attraction to the preposition under can be grouped semantically according to the different senses the preposition conveys, while the cognitive motivation behind the use of the preposition with these nouns can be explained by means of conceptual metaphors, metonymies, and/or image schemas.

\section{Corpora, data, tools, and statistical procedure}

The data under investigation were retrieved from the academic part of the Corpus of Contemporary American English (COCA), a database of texts covering the years between 1990 and 2016. This sub-corpus is composed of more than 103 million words from approximately 100 different peer-reviewed journals. A search engine in this corpus allowed for the extraction of noun collocates for the preposition under in the academic section. The retrieval, however, was restricted to two places to the right of the search 
word (i.e., two words), since it was impossible to extract all rare occurrences of nouns with the preposition under within a larger span position to the right. This technical difficulty arose when the minimum frequency of collocates of the search word was set to one occurrence.

After the retrieval of nouns, each occurrence of a specific noun in the pattern under study was manually examined to identify genuine combinations. All false hits were eliminated from further analysis, and the observed frequencies of the remaining instances of nouns collocating with under were calculated manually by reading concordance lines. Then, all the frequencies necessary to compute the degree of the mutual association between nouns and the preposition were entered into an Excel worksheet and subjected to Schmid's arithmetic measures of attraction and reliance. The percentages resulting from these computations were used as indexes of association strength, so the percentages showed a noun's strength of attraction to or repulsion from the preposition under: the higher the percentage, the stronger the attraction to, and reliance on, the preposition.

The procedure for this quantitative investigation consisted of three stages. At the first stage, the observed frequencies were calculated. With respect to the noun conditions in Table 1, all occurrences of this noun in the under-NOUN pattern were first identified from the corpus, which yielded 2080 results. Then, the total frequency of the noun (conditions) in the corpus was determined, yielding 26,725. Finally, the total frequency of all nouns in the pattern was calculated, resulting in 29,522. These three figures were extracted from the corpus manually by reading concordance lines and counting all the occurrences of the nouns under scrutiny.

Table 1. Co-occurrence table for a quantitative analysis

\begin{tabular}{|c|c|c|c|c|c|}
\hline Noun & A & $\mathbf{x}$ & e & Attraction & Reliance \\
\hline conditions & 2080 & 29522 & 26725 & $7.05 \%$ & $7.78 \%$ \\
\hline
\end{tabular}

Note:

$\mathbf{a}=$ Frequency of noun (e.g., conditions) inthe under-NOUN pattern; $\mathbf{x}=$ Total frequency of all nouns in the pattern; $\mathbf{e}=$ Total frequency of noun (e.g., conditions) in corpora

At the second stage, measures of attraction and reliance were computed. To this end, the frequencies mentioned above were entered into an Excel spreadsheet and submitted to these arithmetic tests. As shown in Table 1, the percentages obtained from the computation of attraction and reliance for the noun conditions are very high in direct comparison with other nouns (see Table 2 for a comparison of scores): $7.05 \%$ and $7.78 \%$, respectively. This means that the noun occurs in $7.05 \%$ of the uses of the construction in the 
corpus. In other words, the word conditions is highly significant because it is a very strongly attracted lexeme of the under-NOUN pattern. In addition, $7.78 \%$ of the occurrences of the same noun are found in this pattern, which means that the lexeme conditions relies on other patterns in the corpus to a larger extent, in a proportion of $92.22 \%$.

At the final step, the nouns were ranked according to their strength of attraction, and the results were interpreted qualitatively and subjectively. The results revealed that there are indeed nouns that are significantly attracted to the preposition under in this pattern, and the results show that the reciprocal interaction between particular nouns and under is determined by different senses, which in turn appear to be motivated by conceptual metaphors, metonymies, and/or image schemas.

\section{The preposition under and its senses}

Even a cursory examination of corpus data reveals subtle semantic differences in the use of the preposition under with its noun collocates. The following examples retrieved from the academic section of COCA illustrate the co-occurrence of this preposition with an array of nouns:

1. He sat down under a tree that was standing by the road.

2. Under this agreement each head of household received 100 acres for his or her family.

3. The educational options grouped under this rubric are not coded separately.

4. The lone female was Tonia Selley, who went under the name of Karla Krimpelien.

5. Ninety-one percent of children with rotavirus were under two years of age.

6. Subsequently, under the influence of outside Islamic extremists, it was "claimed" by Muslims.

7. Accordingly, there was no room for constitutional limits under patriarchal government.

8. The cognitive processes that facilitate this transition are still under investigation.

9. Under circumstances that are not yet fully clear, Iraqi warplanes were flown to Iran.

As shown in the above examples, the preposition under carries multiple senses and collocates with nouns referring to a physical entity (e.g., a tree), an agreement, a rubric, a name, a particular age, influence, government, investigation, and circumstances. In (1) the preposition is used in a spatio-geometric sense to imply 'directly below something'. In example (2) it denotes 'according to a particular agreement', and in (3) it designates 'where something can be found'. In (4), the preposition under is applied to mean 'using a particular name in an official situation'. In (5) under means 'younger than a particular age'. In (6), it denotes 'being affected or controlled by a particular action or situation'. In (7) under is used for stating that a particular government is in power or control. In example (8) it designates 'in the process of being affected by an action', and in (9) it represents 'in the situation when something happens or exists'. 
The definitions of the preposition under in the Macmillian English Dictionary (2nd edition) and the usage examples confirm these meanings. The dictionary, edited by Rundell (2007: 1625), offers the following explanation about the semantic properties of the preposition under, accompanied by the illustrative examples:

10.1. below or covered by something 1a. directly below or at a lower level than something: O We took shelter under an oak tree. 1b. covered by something: 0 She was wearing a money belt under her sweater. 1c. moving to a place that is below something or that is covered by it: o I think the ball rolled under the sofa. 1d. passing below something from one side to the other: o We drove under the bridge and came out into the High Street. 1e. below the surface of water: $\bigcirc$ The ducks kept diving under the water to catch fish. 2. less than a particular amount, or younger than a particular age: $\bigcirc$ There is a working holiday scheme for British citizens, but you have to be under 26. 3. affected by something in the process of being affected or controlled by a particular action, situation, or state: $\bigcirc \mathrm{A}$ number of proposals are under consideration. $\circ$ Police claim the situation is now under control. 4. when particular conditions exist used for saying that something happens when particular conditions exist: $O$ The UN inspectors would be allowed access to the eight sites, but only under certain conditions. 5. according to a rule according to a particular law, agreement, or system: $O$ The boy is considered a minor under British law. 6. when sb is in power or control used for stating that something happens when a particular person or government is in power: o Some former conservatives are returning to the party under the new leader. 7. using a particular name using a particular name in official situations, often a name that is not your own: o Carson had been travelling under a false name. 8. where something can be found if something is under a particular section, word, letter etc., this is where it can be found: oThe tickets should be under the name 'Carlson'(...).

As the dictionary entry for under in (10) reveals, the preposition under has a common tendency to collocate with nouns denoting a physical entity (e.g., tree, sweater, sofa, bridge, or water), a specific age, a law, a section, control, leadership, consideration, and conditions. In the first definition and example, which is a concrete one, we can distinguish between five different subsenses (1a-e), or more specific senses being derived from, included in, or closely related to the basic spatial meaning 'below something'. In this concrete sense, the preposition can be used to specify a location, a motion along a path, and a motion to an end-point (Radden \& Dirven 2007: 313). The remaining senses seem to be figurative extensions of these concrete subsenses pertaining to a vertical orientation and movement (cf. Boers 1996). For example, sense 2 is a metaphorical extension of the concrete sense 'below or covered by something', whereas the preposition in the expression under 26 reflects the metaphor LESS IS DOWN. The sense of the 
preposition under in 3 is motivated by the metaphor CONTROL IS DOWN, an orientational metaphor discussed by Lakoff and Johnson (1980) in the now-classic Metaphors We Live By.

The semantics of the preposition under in English has received much attention among cognitive linguists in recent years. The role of the cognitive motivation underpinning the use and comprehension of this projective preposition has been the subject of both extensive linguistic analysis and empirical research (e.g., Boers 1996; Tyler \& Evans 2003; Lindstromberg 2010). Boers's (1996) study, for example, revealed that the bulk of uses of the preposition are constituted by figurative extensions of the spatial sense, and only approximately $25 \%$ of the instances of under primarily activate the domain of the physical space. The remaining instances are metaphorical extensions based on numerous conceptual metaphors: LESS IS DOWN, BEING SUBJECTED TO CONTROL IS DOWN, COGNITION IS PERCEPTION, etc. Lindstromberg's (2010) study also provided valuable insight into the semantic nature of the preposition under by identifying its basic spatial meanings and metaphors (e.g., POWERLESS IS DOWN, A SITUATION IS A KIND OF COVERING, UNPLEASANT EXPERIENCES ARE BURDENS). Finally, Tyler and Evans (2003: 121-127) found that all meanings of the preposition under are systematically grounded in the nature of human spatio-physical experience, and the original proto-scene provides the foundation for the extension of meaning from the spatial to the more abstract. Tyler and Evans treated the preposition under as being comprised of related concepts that form a semantic network of senses related by degrees, with some senses being more central (protoscene and the 'down' sense) and others more peripheral (the 'less' sense, the 'control' sense, the 'covering' sense, and the 'non-existence' sense). For example, the 'less' sense and the 'control' sense are extensions of the 'down' sense, while the 'covering' sense and the 'non-existence' sense derive from the proto-scene (Tyler \& Evans 2003: 121-127).

Given the semantics of the preposition, we could expect that under is a polysemous preposition co-occurring with a multitude of closely related nouns (i.e., nouns associated with control) in academic discourse, and the reciprocal interaction between the preposition under (its different senses) and its noun collocates can be motivated by conceptual metaphors, metonymies, and/or image schemas.

The application of the corpus-based method allows us to corroborate or refute such pre-set expectations and assumptions. This approach can be employed to uncover and substantiate the existence, and degree, of semantic and distributional differences in the use of the preposition, its collocability with nouns, as well as the semantic restrictions the preposition imposes on the nouns. This substantiation may be provided by virtue of indicating the nouns that co-occur more or less frequently with the preposition. 


\section{Findings and discussion}

The data excerpted from the corpus included 2790 types of nouns derived from a multitude of semantic domains, out of which 1450 occurred only once in the pattern. Due to space limitations, this section will solely report the results for the most strongly attracted nouns of the combination. Table 2 below exhibits the results of the measures of attraction and reliance for the 30 most strongly attracted nouns of this pattern. It also provides the observed frequency of nouns in the pattern under study, the total frequency of all nouns in the pattern, and the frequency of their occurrence in the whole corpus.

Table 2 . The results of attraction and reliance for the 30 most strongly attracted nouns

\begin{tabular}{|c|c|c|c|c|c|c|}
\hline rank & nouns & $\mathbf{a}$ & $\mathbf{x}$ & $\mathrm{E}$ & attraction & reliance \\
\hline 1. & conditions & 2080 & 29522 & 26725 & $7.05 \%$ & $7.78 \%$ \\
\hline 2. & circumstances & 1313 & 29522 & 8127 & $4.45 \%$ & $16.16 \%$ \\
\hline 3. & control & 1043 & 29522 & 50704 & $3.53 \%$ & $2.06 \%$ \\
\hline 4. & pressure & 871 & 29522 & 14435 & $2.95 \%$ & $6.03 \%$ \\
\hline 5. & law & 845 & 29522 & 37705 & $2.86 \%$ & $2.24 \%$ \\
\hline 6. & section & 612 & 29522 & 23982 & $2.07 \%$ & $2.55 \%$ \\
\hline 7. & influence & 460 & 29522 & 24102 & $1.56 \%$ & $1.91 \%$ \\
\hline 8. & age & 454 & 29522 & 38252 & $1.54 \%$ & $1.19 \%$ \\
\hline 9. & rule & 446 & 29522 & 12140 & $1.51 \%$ & $3.67 \%$ \\
\hline 10. & auspices & 439 & 29522 & 500 & $1.49 \%$ & $87.80 \%$ \\
\hline 11. & consideration & 383 & 29522 & 12037 & $1.30 \%$ & $3.18 \%$ \\
\hline 12. & direction & 362 & 29522 & 9430 & $1.23 \%$ & $3.84 \%$ \\
\hline 13. & leadership & 361 & 29522 & 15536 & $1.22 \%$ & $2.32 \%$ \\
\hline 14. & study & 345 & 29522 & 117059 & $1.17 \%$ & $0.29 \%$ \\
\hline 15. & supervision & 312 & 29522 & 3003 & $1.06 \%$ & $10.39 \%$ \\
\hline 16. & attack & 299 & 29522 & 6439 & $1.01 \%$ & $4.64 \%$ \\
\hline 17. & title & 285 & 29522 & 6640 & $0.97 \%$ & $4.29 \%$ \\
\hline
\end{tabular}


$\mathbf{a}=$ Frequency of noun (e.g., conditions) in the under-NOUN pattern; $\mathbf{x}=$ Total frequency

of all nouns in the pattern; $\mathbf{e}=$ Total frequency of noun (e.g., conditions) in corpora

\begin{tabular}{|c|l|c|c|c|c|c|}
\hline rank & nouns & $\mathbf{a}$ & $\mathbf{X}$ & $\mathrm{E}$ & attraction & reliance \\
\hline $\mathbf{1 8 .}$ & years & 278 & 29522 & 89313 & $0.94 \%$ & $0.31 \%$ \\
\hline $\mathbf{1 9 .}$ & investigation & 256 & 29522 & 7943 & $0.87 \%$ & $3.22 \%$ \\
\hline $\mathbf{2 0 .}$ & stress & 245 & 29522 & 14131 & $0.83 \%$ & $1.73 \%$ \\
\hline $\mathbf{2 1 .}$ & discussion & 222 & 29522 & 21722 & $0.75 \%$ & $1.02 \%$ \\
\hline $\mathbf{2 2 .}$ & scrutiny & 212 & 29522 & 1699 & $0.72 \%$ & $12.48 \%$ \\
\hline $\mathbf{2 3 .}$ & rubric & 199 & 29522 & 1161 & $0.67 \%$ & $17.14 \%$ \\
\hline $\mathbf{2 4 .}$ & review & 199 & 29522 & 24139 & $0.67 \%$ & $0.82 \%$ \\
\hline $\mathbf{2 5 .}$ & guidance & 199 & 29522 & 5851 & $0.67 \%$ & $3.40 \%$ \\
\hline $\mathbf{2 6 .}$ & construction & 192 & 29522 & 10352 & $0.65 \%$ & $1.85 \%$ \\
\hline $\mathbf{2 7 .}$ & development & 181 & 29522 & 68049 & $0.61 \%$ & $0.27 \%$ \\
\hline $\mathbf{2 8 .}$ & president & 174 & 29522 & 24047 & $0.59 \%$ & $0.72 \%$ \\
\hline $\mathbf{2 9 .}$ & name & 174 & 29522 & 14825 & $0.59 \%$ & $1.17 \%$ \\
\hline $\mathbf{3 0 .}$ & threat & 169 & 29522 & 9541 & $0.57 \%$ & $1.77 \%$ \\
\hline
\end{tabular}

The results shown in Table 2 are sorted according to the measure of attraction. The top of the table includes relatively common nouns, such as conditions, circumstances, control, pressure, or law. The most logical explanation for this is that the total frequency of these nouns in COCA overall is likely to exert a profound effect upon the likelihood of their occurrence in the pattern under investigation. For example, conditions (attraction score 7.05\%) and circumstances (attraction score 4.45\%) obtained much higher scores for attraction than name (attraction score $0.59 \%$ ) and threat (attraction score $0.57 \%$ ), as conditions and circumstances occurred much more frequently in the pattern than name and threat. By contrast, the list for reliance comprises much higher scores for less common nouns occurring in the pattern, such as auspices (reliance score 87.80\%), supervision (reliance score $10.39 \%$ ), and scrutiny (reliance score 12.48\%), since the formula employed for the calculation of reliance takes the total frequency of each noun in the corpus into consideration. For instance, although the noun conditions occurs much more frequently in the pattern than auspices, the latter achieves a much higher score for reliance because its overall frequency of occurrence in the corpus is much lower (500 occurrences). 
Consequently, the reciprocal association between auspices and the preposition under also appears to be more significant (87.80\%).

The results support the predictions that the semantic relationships between different uses of the preposition under and its noun collocates are based on specific metaphorical correspondences, metonymies and/or image schemas. Furthermore, the suggestions concerning the co-occurrence of the preposition with specific categories of nouns are also confirmed. The findings reveal that some nouns occur more frequently with the preposition under than others. The two most strongly associated nouns are conditions and circumstances. The percentages resulting from the calculation of attraction for these lexemes are high in comparison to other lexemes: $7.05 \%$ and $4.45 \%$, respectively.The use of these nouns with under can be illustrated by the following sentences:

\section{The latter predisposes one to brain hemorrhage, particularly under conditions of anticoagulation.}

\section{Under such circumstances, reliability and validity of assessment become crucial.}

In these examples, under is used to say that 'something happens when particular conditions exist'. This sense seems to be a metaphorical extension of the 'covering' sense: conditions and circumstances limiting or affecting something are construed as objects covering something. In other words, the preposition encodes the spatial relation of covering, while the abstract concepts conditions and circumstances are conceptualized in terms of this relation, thereby making reference to the SITUATIONS ARE COVERINGS metaphor, a metaphor Lindstromberg (2010: 164) mentioned, in which situations and states such as circumstances and conditions are conceived as coverings.

The second set of the most strongly attracted nouns collocating with the preposition under consists of lexemes pertaining to being subject to force, power, control, law, or rules. Its leading lexeme control, ranked third, is accompanied by law, influence, rule, auspices, direction, leadership, supervision, guidance, and president in ranks 5, 7, 9, 10, $12,13,15,25$, and 28. In such combinations, the preposition under is used in the 'control' sense as a metaphorical extension of the 'down' sense. In addition, under refers to the UP-DOWN image schema and the FORCE image schema: entities being down are affected and controlled by some forces being up. The preposition under encodes the up-down spatial relation between two entities, and then this relation is used to understand the abstract concept control, hence activating the LACK OF CONTROL IS DOWN metaphor (Lakoff \& Johnson 1980; Kövecses 2010), which is also referred to as POWERLESSNESS IS DOWN (Lindstromberg 2010) or as BEING SUBJECT TO CONTROL OR FORCE IS DOWN (Boers 1996).

If we consider all significant combinations of nouns with the preposition under in the pattern, it turns out that the nouns mentioned above in fact constitute the most strongly 
associated nouns occurring with the preposition in the ranking list. The scores of attraction and reliance reveal that the noun control accounts for 3.53\% of the uses of all nouns co-occurring with under in the academic section of COCA, and 2.06\% of uses of the same noun are found in the pattern. The lexeme is thus attracted to the pattern in a proportion of $3.53 \%$ and relies on the pattern in a proportion of $2.06 \%$. Hence, control is one of the most significant lexemes collocating with the preposition.

The following examples are provided to illustrate the use of the preposition under reflecting the general metaphor BEING SUBJECT TO CONTROL OR FORCE IS DOWN:

13. Under prior law, the distance test was 35 miles.

14. The Pakistani drone program may not long remain under the auspices of the CIA.

15. Obama once said about the prospects for health reform under his leadership.

Since under is associated with downness, it figures in many expressions of the systematic metaphor whereby being subject to control or force is considered being down. For example, the expression under prior law in (13) designates 'being subjected to a law passed by a parliament', whereas under the auspices of the CIA in (14) is used to denote 'to be under the supervision, control, or management of an organization or a country'. The phrase under his leadership in (15) refers to 'the rules or people controlling a country or organization'.

Other uses of the preposition reflecting the same metaphor are as shown in (16) and (17) below:

16. Foster came to him that day with a suspicion that Zopatti was under the influence of some substance.

17. They were much higher than they are under President Obama.

In (16) under means 'affected', while the whole expression refers to 'being affected by a substance'. In (17), under collocates with President Obama, a noun that can be conceptually interpreted with reference to the metonymy A RULER FOR THE PERIOD OF HIS RULE. President Obama metonymically stands for the period of his authority.

The third group in the ranking is constituted by a range of nouns denoting unpleasant experiences. Its main lexeme pressure (attraction score 2.95\%) ranked number four and is followed by attack, stress, and threat in ranks 16, 20, and 30, respectively. Pressure and attack obtained much higher scores for attraction (2.95\% and 1.01\%) than stress (attraction score 0.83\%) and threat (attraction score 0.57\%), since they occurred much more frequently in the pattern. Stress and threat obtained lower scores for reliance (1.73\% and $1.77 \%$, respectively) than pressure and attack (6.03\% and $4.64 \%)$, as they occurred more frequently in other contexts. 
The preposition under collocating with this set of nouns conveys the sense of 'being affected or controlled by a particular action, situation, or state', thereby reflecting the general metaphor BEING SUBJECT TO CONTROL OR FORCE IS DOWN in the sense of being affected by unpleasant experiences. In other words, the abstract concepts stress, threat, pressure, and attack, which are associated with unpleasant experiences affecting or controlling someone, are understood in terms of downness. This usage of under also seems to be related to the UP-DOWN schema and the CONTACT schema, which are consistent with the physical experience of carrying a burden. Hence, this sense of under can be additionally interpreted with respect to the metaphor UNPLEASANT EXPERIENCES ARE BURDENS (see Lindstromberg 2010 for a detailed discussion of this metaphor), whereby unwelcome states and events (such as pressure, stress, or attack) are construed as something oppressive and heavy that weigh down the subject (sufferer) from above. The corpus data in (18), (19), and (20) below serve as illustrations of this phenomenon:

18. Khartoum is increasingly coming under pressure from all sides.

19. Table one is a brief list of important basic facts in dealing with children under stress.

20. The Vincennes was never under attack by Iranian aircraft.

In (18), under pressure is used to denote 'being made to feel forced to do something by arguments, threats', etc. Under stress in (19) means 'affected by a worried or nervous feeling', while under attack in (20) designates 'affected by an enemy attack'. This last expression may also refer to 'strong criticism'.

The next category comprises section, title, rubric, and name in ranks 6, 17, 23, and 29. In these combinations, the preposition under is used for stating that 'something can be found under a particular section, title, name', etc., thereby evoking the UP-DOWN image schema, where written discourse may be conceived as a subdomain of physical space. It is two-dimensional and its vertical axis is determined by cultural conventions (Boers 1996: 45). The uses of under with these nouns can also be interpreted with reference to the metonymy A PART FOR THE WHOLE, where a title or heading is used metonymically to stand for the text (a piece of written discourse). The corpus data in (21), (22), and (23) illustrate this point.

21. Social workers can remove people from their homes under section $\mathbf{4 7}$ of the National Assistance Act 1948.

22. He has published a novel under the title My Memorial.

23. Hence, the courses described earlier are listed under the rubric CSCL.

In (21), the phrase under section denotes 'found under a piece of writing that may be considered separately', and it occupies the highest position among the terms 
in this category. Section is attracted to the pattern in a proportion of $2.07 \%$ and relies on this construction in a proportion of $2.55 \%$, which means that the lexeme section is used more frequently (in a proportion of 97.45\%) in other contexts. By comparison, title and rubric are less significant lexemes of the pattern (attraction scores $0.97 \%$ and $0.67 \%$ ) but rely on the pattern to a larger degree (reliance scores $4.29 \%$ and $17.14 \%$ ). The term title is used to denote 'the title of a novel written at the top of a page or piece of writing', whereas rubric refers to 'the name of a particular section under which particular courses are listed'.

The expression under name can be motivated by the metonymy THE WHOLE FOR ITS PARTS, in which the category (social studies) stands for its members (geography and history), since those members (parts) can be found under that category (the whole), as shown in (24):

24. Presently, however, geography is taught together with history under the name of social studies from the 1st until the 7 th grade.

According to Boers (1996: 50), a piece of written discourse can serve as a mental construct to define a particular category, while under can be employed to locate members of that category.

Other nouns that are strongly attracted to the preposition in question are terms that refer to growth and quantity, such as age and years. Age, ranked eighth, is a more strongly attracted lexeme (attraction score 1.54\%) than years, which ranked 18th. Note that age relies on the pattern to a higher degree (reliance score 1.19\%) as compared to years (0.31\%), which means that this term appears more frequently than years in the pattern with under. Examples showing the use of the preposition with these nouns are listed below:

25. About 20,000,000 children under age 17 have never seen a dentist.

26. Most abusive fractures are in children under 3 years.

In these examples, under conveys a conventional meaning of 'less', a sense that results from an experiential correlation between a vertical orientation and quantity. Being down directly implicates possessing less of something. Hence, this sense rests on the metaphor LESS IS DOWN, which operates with two notions: quantity and verticality (cf. Lakoff \& Johnson 1980; Kövecses 2010), where quantity is understood metaphorically in terms of verticality. More specifically, age and years reference the concept of SCALE, which can be conceptualized either as a vertical or horizontal axis and both mean 'younger than a specific age'. The metaphor LESS IS DOWN has a metonymic basis 
here, since vertical extension can be used to stand for growth within the source domain of physical space (cf. Boers 1996: 46).

Among the most significant lexemes in both lists, there are also terms such as consideration, study, investigation, discussion, scrutiny, and review. The first lexeme is attracted to the preposition in a proportion of $1.30 \%$ and relies on the preposition under in a proportion of $3.18 \%$. In contrast, terms such as scrutiny and review seem to be much less important nouns collocating with under since their scores for attraction are lower (attraction scores $0.72 \%$ and $0.67 \%$ ). Some examples illustrating the co-occurrence of these nouns with under are presented in (27), (28), and (29) below.

27. Remedial matters such as relocation and compensation were under consideration.

28. The cognitive processes that facilitate this transition are still under investigation.

29. The course of true love was under intense scrutiny in postwar America.

The preposition under collocating with these nouns conveys the meaning in the process of being affected or controlled by a particular action, situation, or state: more specifically, in the process of being discussed, considered or investigated', thus reflecting the BEING SUBJECT TO CONTROL OR FORCE IS DOWN metaphor in the sense of 'being subjected to analysis'. This meaning seems to be a metaphorical extension of the 'down' sense: objects of study that are placed down or under a microscope are controlled and examined very carefully from the perspective of verticality. Thus, the up-down orientation can also be used metaphorically to understand target concepts related to the process of examining something.

Finally, the ranking list in Table 2 contains nouns such as construction and development, which occupy ranks 26 and 27, respectively. Examples illustrating the use of these nouns with the preposition are presented in (30) and (31) below.

30. Nearby, three villas for foreign archaeologists are under construction.

31. The mechanical subsystem (MS) of the alpha tool has been under development by Nikon.

In such uses, the preposition encodes a metaphorical extension of the down sense and denotes 'in the process of being affected or controlled by a state, situation, or action', hence being based on the general metaphor BEING SUBJECT TO CONTROL OR FORCE IS DowN in the sense of 'being subjected to the process of change or improvement'. Under construction in (30), means 'being in the process of building', and can be considered to be directly motivated by a specific subtype of the general metaphor BEING SUBJECTED TO THE PROCESS OF BUILDING IS DOWN. In (31), under development means 'being in the process of creating a new system', which can be seen as being motivated by the 
sub-metaphor BEING SUBJECTED TO THE PROCESS OF CHANGE, GROWTH OR IMPROVEMENT IS DOWN.

\section{Concluding remarks}

In conclusion, the quantitative investigation of nouns co-occurring with under in the under-NOUN pattern indicated that there are indeed nouns that demonstrate strong associations with the preposition under, and the mutual attraction between under and its noun collocates seems to be determined by the different senses of this preposition used in specific contexts, which are motivated by conceptual metaphors, metonymies, and/ or image schemas. For example, as noted in section 5, the 'control' sense of the preposition in combinations such as under control, under law, under leadership, or under president is highly motivated by the metaphor BEING SUBJECT TO CONTROL OR FORCE IS DOWN. Thus, under tends to collocate quite frequently with a range of nouns associated with some kind of control, power, force, or law.

The most obvious finding to emerge from this study is that there are several groups of nouns that are closely related semantically and are strongly associated with the preposition under in the under-NOUN pattern. More specifically, the results indicate that in academic discourse the preposition displays a strong tendency to occur with nouns pertaining to physical situations (e.g., conditions, circumstances), control and law (e.g., influence, rule, auspices, leadership, supervision, president), unpleasant experiences and situations (e.g., pressure, attack, stress, threat), a title and heading (e.g., section, title, rubric, name), a particular age and amount (e.g., age, years), or cognition and perception (e.g., consideration, study, investigation, discussion, scrutiny). Also, the co-occurrence of the noun auspices with the preposition under is more significant than its use in other constructions.

The results also revealed that terms (e.g., influence, pressure, section, consideration) that are closely associated with, or directly related to, control or law, unpleasant experiences or situations, titles or headings, and cognition or perception constitute the bulk of the most strongly attracted lexemes in the ranking list. A possible explanation for the co-occurrence of those nouns with the preposition under in academic discourse may be the semantic restrictions imposed by the preposition (i.e., the kinds of meanings conveyed by the preposition in particular contexts) and the nature and specificity of the academic register. For example, in (27), (28), and (29), under bears the meaning 'in the process of being discussed, considered or investigated', thereby introducing semantic restrictions upon the types of nouns with which the preposition collocates. Consequently, its collocability in these contexts is restricted to the nouns associated with the act of investigating or examining something. In academic discourse, such combinations are used to present, interpret and/or comment on the results of studies such as in reference to the process of attempting to discover all the details or facts. 
The frequent occurrence of the preposition under with nouns such as stress, threat, conditions, and consideration confirms the prediction that the preposition under demonstrates a marked preference for nouns referring to abstract notions that mainly carry figurative meanings. The results of the quantitative analysis indicate that the figurative senses of under pertaining to conditions and circumstances, control and law, titles and headings, unpleasant experiences and situations, as well as cognition and perception predominate in the academic section of COCA. These findings support Boer's (1996) conclusions regarding the occurrence of under in three types of corpora. Boers (1996: 40) found that from a statistical standpoint, figurative senses are more frequent than literal ones in the L.O.B Corpus, the Brown Corpus, and the Corpus of English conversation. More precisely, out of 1374 instances of under, literal senses accounted for approximately 25\% of all the instances, or 352 total occurrences: 164 in the L.O.B corpus, 175 in the Brown corpus, and 13 in the corpus of English conversation. A cursory glance at the ranking list in Table 2 reveals that the frequency of figurative senses of under in academic discourse substantially exceeds the frequency of occurrence of literal senses.

After a careful examination of the results, it can be concluded that a quantitative, corpus-driven approach can provide detailed statistical description of the nouns collocating with under in the pattern in question and identify minor distributional differences in the occurrence of these nouns in the pattern under study. The quantitative method adopted in this study proved to be a useful technique allowing for the determination of frequent and rare occurrences of nouns in the pattern, so it can be successfully employed for the investigation of nouns collocating with other prepositions. Future research might focus on comparing and contrasting nouns co-occurring with prepositions such as underneath, beneath, below, down, above, over, or behind.

Finally, given that the current investigation was limited to the academic sub-corpus of COCA, it would be worthwhile to carry out a comparative study of nouns co-occurring with the preposition under in other sections of COCA and across different types of written and spoken registers due to the possible existence of slight variations in their occurrence. Such a quantitative analysis could reveal subtle distributional differences in the occurrence of nouns in the pattern under consideration.

\section{References}

Achard, M. \& Niemeier, S. (eds.). 2004. Cognitive Linguistics, Second Language Acquisition, and Foreign Language Teaching, Vol. 18. Berlin/New York: Walter de Gruyter.

Arnon, I. \& Snider, N. 2010. More than words. Frequency effects for multi-word phrases. Journal of Memory and Language 62: 67-87.

Boers, F. 1996. Spatial Prepositions and Metaphor. A Cognitive Semantic Journey along the UP-DOWN and the FRONT-BACK Dimensions. Tuebingen, Germany: Gunter Narr Verlag. 
Boers, F. \& Demecheleer, M. 1998. A cognitive semantic approach to teaching prepositions. English Language Teaching Journal 53: 197-204.

Brenda, M. 2014. The Cognitive Perspective on the Polysemy of the English Spatial Preposition 'over'. Newcastle upon Tyne: Cambridge Scholars Publishing.

Brugman, C. 1988. The Story of 'over': Polysemy, Semantics and the Structure of the Lexicon. New York: Garland.

Bybee, J. 2010. Language, Usage, and Cognition. Cambridge: Cambridge University Press. Bybee, J. \& Hopper, P. (eds.). 2001. Frequency and the Emergence of Linguistic Structure. Amsterdam: John Benjamins.

Cho, K. 2010. Fostering the acquisition of English Prepositions by Japanese learners with networks and prototypes. In: S. D. Knop, F. Boers \& A. D. Rycker (eds.), Fostering Language Teaching Efficiency Through Cognitive Linguistics, 259-275. Berlin: Mouton de Gruyter.

Dewell, R. 1994. Over again: Image-schema transformations in semantic analysis. Cognitive Linguistics 5(4): 451-480.

Diessel, H. 2015. Usage-based construction grammar. In: E. Dąbrowska \& D. Divjak (eds.), Handbook of Cognitive Linguistics, 295-321. Berlin: Mouton de Gruyter.

Diessel, H. 2017. Usage-based linguistics. In: M. Aronoff (ed.), Oxford Research Encyclopedia of Linguistics. New York: Oxford University Press.

Evans, V. \& Tyler, A. 2004a. Spatial experience, lexical structure and motivation: The case of in. In: G. Radden \& K.-U. Panther (eds.), Studies in Linguistic Motivation, 157-192. Berlin: Mouton de Gruyter.

Evans, V. \& Tyler, A. 2004b. Rethinking English prepositions of movement: The case of to and through. In: H. Cuyckens, W. deMulder \& T. Mortelmans (eds.), Adpositions of Movement (Belgian Journal of Linguistics, 18), 247-270. Amsterdam: John Benjamins.

Evans, V. \& Tyler, A. 2005. Applying cognitive linguistics to pedagogical grammar: The English prepositions of verticality. Revista Brasileira de Lingüistica Aplicada 5(2): $11-42$.

Goldberg, A. E. 1995. Constructions: A Construction Grammar Approach to Argument Structure. Chicago: University of Chicago Press.

Goldberg, A. E. 2006. Constructions at Work. The Nature of Generalization in Language. Oxford: Oxford University Press.

Goldberg, A. E. 2013. Constructionist approaches to language. In: T. Hoffmann and G. Trousdale (eds.), Handbook of Construction Grammar, 15-48. Oxford: Oxford University Press.

Hampe, B. 2005. Image schemas in cognitive linguistics: introduction. In: B. Hampe (ed.), From Perception to Meaning: Image Schemas in Cognitive Linguistics, 1-14. Berlin: Mouton de Gruyter. 
Hilpert, M. 2014. Construction Grammar and its Application to English. Edinburgh: Edinburgh University Press.

Johnson, M. 1987. The Body in the Mind: The Bodily Basis of Reason, Thought and Imagination. Chicago: University of Chicago Press.

Kövecses, Z. 2006. Language, Mind and Culture. Oxford: Oxford University Press.

Kövecses, Z. 2010. Metaphor: A Practical Introduction. 2nd ed. Oxford: Oxford University Press.

Kövecses, Z. 2015. Where Metaphors Come From: Reconsidering Context in Metaphor. Oxford: Oxford University Press.

Kövecses, Z. 2016. Contextual factors in metaphor creation in discourse. In: M. Fabiszak, K. Krawczak \& K. Rokoszewska (eds.), Categorization in Discourse and Grammar, 21-32. Frankfurt am Main: Peter Lang.

Kövecses, Z. \& Radden, G. 1998. Metonymy: Developing a cognitive linguistic view. Cognitive Linguistics 9: 37-77.

Lakoff, G. 1987. Women, Fire, and Dangerous Things: What Categories Reveal about the Mind. Chicago: University of Chicago Press.

Lakoff, G. \& Johnson, M. 1980. Metaphors We Live By. Chicago: University of Chicago Press.

Langacker, R. W. 1987. Foundations of Cognitive Grammar. Theoretical Prerequisites. Vol. II. Stanford: Stanford University Press.

Langacker, R. W. 2008. Cognitive Grammar. A Basic Introduction. Oxford: Oxford University Press.

Lindstromberg, S. 1996. Prepositions: Meaning and method. ELT Journal 50(3): 225-236.

Lindstromberg, S. 2001. Preposition entries in UK monolingual learner's dictionaries: Problems and possible solutions. Applied Linguistics 22(1): 79-103.

Lindstromberg, S. 2010. English Prepositions Explained. 2nd ed. Amsterdam: John Benjamins.

Littlemore, J. 2009. Applying Cognitive Linguistics to Second Language Learning and Teaching. Basingstoke: Palgrave Macmillan.

Mandler, J. M. \& Pagan Cánovas, C. 2014. On defining image schemas. Language and Cognition 6: 510-532.

Oakley, T. 2007. Image schemas. In: D. Geeraerts \& H. Cuyckens (eds.), The Oxford Handbook of Cognitive Linguistics, 214-235. Oxford: Oxford University Press.

Radden, G. \& Dirven, R. 2007. Space and extensions of space. In: G. Radden \& R. Dirven (eds.), Cognitive English Grammar: Cognitive Linguistics in Practice 2, 303-334. Amsterdam: John Benjamins.

Rundell, M. (ed.). 2007. Macmillan English Dictionary for Advanced Learners. 2nd ed. Oxford: Macmillan Education. 
Schmid, H.-J. 2000. English Abstract Nouns as Conceptual Shells. From Corpus to Cognition. Berlin/New York: Mouton de Gruyter.

Schmid, H.-J. \& Küchenhoff, H. 2013. Collostructional analysis and other ways of measuring lexicogrammatical attraction: Theoretical premises, practical problems and cognitive underpinnings. Cognitive Linguistics 24(3): 531-577.

Tyler, A. \& Evans, V. 2001. Reconsidering prepositional polysemy networks: The case of over. Language 77(4): 724-765.

Tyler, A. \& Evans, V. 2003. The Semantics of English Prepositions. Spatial Scenes, Embodied Meaning and Cognition. Cambridge: Cambridge University Press.

\section{Data sources}

The Corpus of Contemporary American English (COCA). Available from https://www.corpusdata.org/purchase.asp

$$
* * *
$$

Jarosław Wiliński is an Assistant Professor at the Institute of Linguistics and Literary Studies at Siedlce University of Natural Sciences and Humanities. He is the author of several articles and book chapters on applications of cognitive linguistics in onomasiological lexicography and on the use of quantitative methods in linguistic research. His areas of interest include cognitive and corpus linguistics, lexicology, phraseology, and onomasiological lexicography. His current research focuses on applications of cognitive linguistics in the compilation of thematic reference works and on a quantitative corpus-based investigation of grammatical constructions, collocations, and metaphors. 